\title{
Slow $\beta$ relaxation in the La-based metallic glasses based on mechanical spectroscopy measurements
}

\author{
J.C. Qiao ${ }^{\mathrm{a}, b^{*}}$, J.M. Pelletier $^{\mathrm{b}}$, N. Lic ${ }^{\mathrm{c}}$, D. Crespo ${ }^{\mathrm{d}}, \mathrm{Y}$ Yao $^{\mathrm{a},}{ }^{*}$ \\ ${ }^{a}$ School of Mechanics, Civil Engineering and Architecture, Northwestern Polytechnical University, \\ Xi'an 710072, P. R. China \\ ${ }^{b}$ Université de Lyon, MATEIS, UMR CNRS5510, Bat. B. Pascal, INSA-Lyon, F-69621 Villeurbanne \\ cedex, France \\ ${ }^{c}$ Department of Materials Science and Engineering and State Key Lab for Materials Processing \\ and Die \& Mould Technology, Huazhong University of Science and Technology, Wuhan 430074, \\ China \\ ${ }^{d}$ Departament de Física, EETAC, Universitat Politècnica de Catalunya, 08860-Castelldfels, \\ Barcelona, Spain
}

(Submitted to Journal of Iron and Steel Research, International)

Revised version: January 26, 2017

*Corresponding author:

Dr. J.C. Qiao

E-mail address: qjczy@hotmail.com

Dr. Y. Yao

E-mail address: yaoy@nwpu.edu.cn 


\begin{abstract}
The intrinsic structural heterogeneities of amorphous alloys are closely related to the thermodynamics and dynamical behavior, such as relaxation/crystallization, glass transition and plastic deformation. However, the structural information is submerged into the meta-stable disordered long-range structure, which makes it difficult to explore the structural heterogeneities of amorphous alloys. In the framework of the mixing enthalpy of constituent atoms, we found that $\beta$ relaxation is less evident by the addition of the $\mathrm{Cu}$ to replace the $\mathrm{Ni}$ in the LaCuNiAl glassy alloy. By introducing $\mathrm{Cu}$ into the LaNiAl metallic glass, the mixing enthalpy is less negative, which leads to less pronounced $\beta$ relaxation of the metallic glasses. The $\alpha$ relaxation of the La-based metallic glasses can be described by a Kohlrausch-Williams-Watts (KWW) function with a Kohlrausch exponent $\beta_{\mathrm{KWw}} \sim 0.5$. It is noted that physical aging above the glass transition temperature induces a decrease of $\beta$ relaxation intensity in the La-based metallic glass.
\end{abstract}

Keywords: Metallic glass; Mechanical relaxation; $\beta$ relaxation; Mixing enthalpy

\title{
1 Introduction
}

Metallic glasses exhibit unique characteristics, such as special physical, chemical and mechanical behavior, which are associated with the intrinsic disordered atomic structure $^{[1-3]}$. Unlike the conventional metallic alloys, metallic glasses are prepared through rapid solidification process. As a result, the as-cast state of the metallic glasses stays in a non-equilibrium state below the glass transition temperature $\left(T_{g}\right)$.

It is well accepted that there is only a single relaxation process at high temperature in the liquid ${ }^{[4-6]}$. When the temperature decreases and approaches $T_{g}$, relaxation splits into two processes at a critical temperature: $\alpha$ (primary) and $\beta$ (secondary) relaxation. It has been proven that $\alpha$ relaxation is associated with the glass transition phenomenon of glassy materials and is related to correlated movements of atoms (or molecules). $\alpha$ relaxation of amorphous materials shows non-Arrhenius behavior. In contrast, the $\beta$ relaxation (also called Johari-Goldstein relaxation) is a fast process which remains in the glass state. Many investigations have proved that the $\beta$ relaxation of glassy materials is essential to understand the glass transition phenomenon, as well as diffusion and the mechanical properties of the glass.

It should be noted that $\beta$ relaxation is the main source of dynamics in the glassy state as the $\alpha$ relaxation disappears below the $T_{g}$. However, the specific connection 
between these two relaxation modes and the fundamental physical mechanism has not yet been fully understood. Available experimental data show either a "shoulder" or "excess wing" of loss modulus below $T_{g}$ for many metallic glasses ${ }^{[7-10]}$. It is reported that some La-based metallic glasses show a pronounced slow $\beta$ relaxation ${ }^{[11-19]}$, which provides an excellent model alloy to study the dynamic mechanical behavior by mechanical spectroscopy. In the current work, the dynamic mechanical behavior of Labased metallic glasses was studied by mechanical spectroscopy with various testing temperatures and frequencies. It is found that the $\beta$ relaxation is strongly dependent on the large mixing enthalpy for all the constitute atoms of metallic glasses.

\section{Experimental Procedures}

$\mathrm{La}_{60} \mathrm{Ni}_{15} \mathrm{Al}_{25-\mathrm{x}} \mathrm{Cu}_{\mathrm{x}}\left(\mathrm{x}=0,5,10\right.$ and 15) (atomic \%), $\mathrm{La}_{55} \mathrm{Al}_{25} \mathrm{Ni}_{15} \mathrm{Cu}_{5}$ and $\mathrm{La}_{60} \mathrm{Al}_{20} \mathrm{Ni}_{15} \mathrm{Cu}_{5}$ amorphous alloys were prepared by the arc-melting technique in a Tigettered flowing argon atmosphere. The master alloys of the La-based metallic glasses were re-melted at least four times in order to ensure chemical homogeneity. Plate samples of the La-based metallic glasses with a thickness of approximately $0.5 \mathrm{~mm}$ were produced by copper mould suction casting. The amorphous nature of the metallic glasses was characterized by a commercial X-ray diffraction (XRD) instrument with $\mathrm{Cu} \mathrm{K} \alpha$ radiation (D8, Bruker AXS Gmbh, Germany) at the room temperature.

The dynamic mechanical behavior of the La-based metallic glasses was measured in an inverted torsion pendulum-based mechanical spectrometer, with varied testing temperature and frequency. The strain amplitude during the measurement is lower than $10^{-4}$, the experimental details have been described by Etienne et al ${ }^{[20]}$. The samples for the mechanical spectroscopy measurement have approximate dimensions of $30 \mathrm{~mm}$ (length) $\times 2 \mathrm{~mm}$ (width) $\times 0.5 \mathrm{~mm}$ (thickness) and the experiments have been performed in a high vacuum environment.

\section{Results and discussions}

Mechanical spectroscopy, also called dynamic mechanical analysis, is a powerful tool to study the viscoelastic properties of glassy materials. During the mechanical spectroscopy testing, the induced strain is measured when a sinusoidal stress is applied. The complex modulus $\mathrm{G}^{*}=\mathrm{G}^{\prime}+i \mathrm{G}^{\prime \prime}$ is recorded during the deformation. Here, $\mathrm{G}^{\prime}$ is the storage modulus and $\mathrm{G}^{\prime \prime}$ is the loss modulus.

Fig.1 (a) and (b) show the normalized storage modulus $\mathrm{G}^{\prime} / G u$ and the loss modulus $\mathrm{G}^{\prime \prime} / \mathrm{Gu}$ of the $\mathrm{La}_{60} \mathrm{Al}_{25} \mathrm{Ni}_{5} \mathrm{Cu}_{10}$ metallic glass as a function of temperature at a given driving frequency, respectively (the heating rate is a constant: $3 \mathrm{~K} / \mathrm{min}$ ). Here, $\mathrm{Gu}$ is the 
non-relaxed modulus, which is equal to the storage modulus $\mathrm{G}^{\prime}$ at ambient temperature. A peak in the loss modulus, identified as $\beta$ relaxation, is noted around $350 \mathrm{~K}$. By increasing the temperature, the storage modulus decreases while the loss modulus increases until reaching a maximum; this phenomenon corresponds to the glass transition behaviour in glassy materials. The process is called $\alpha$ relaxation. Above the glass transition the storage and loss moduli increase again, which is associated with the crystallization behaviour of the metallic glasses. The results are in good accordance with other metallic glasses ${ }^{[11,13,21,22]}$.
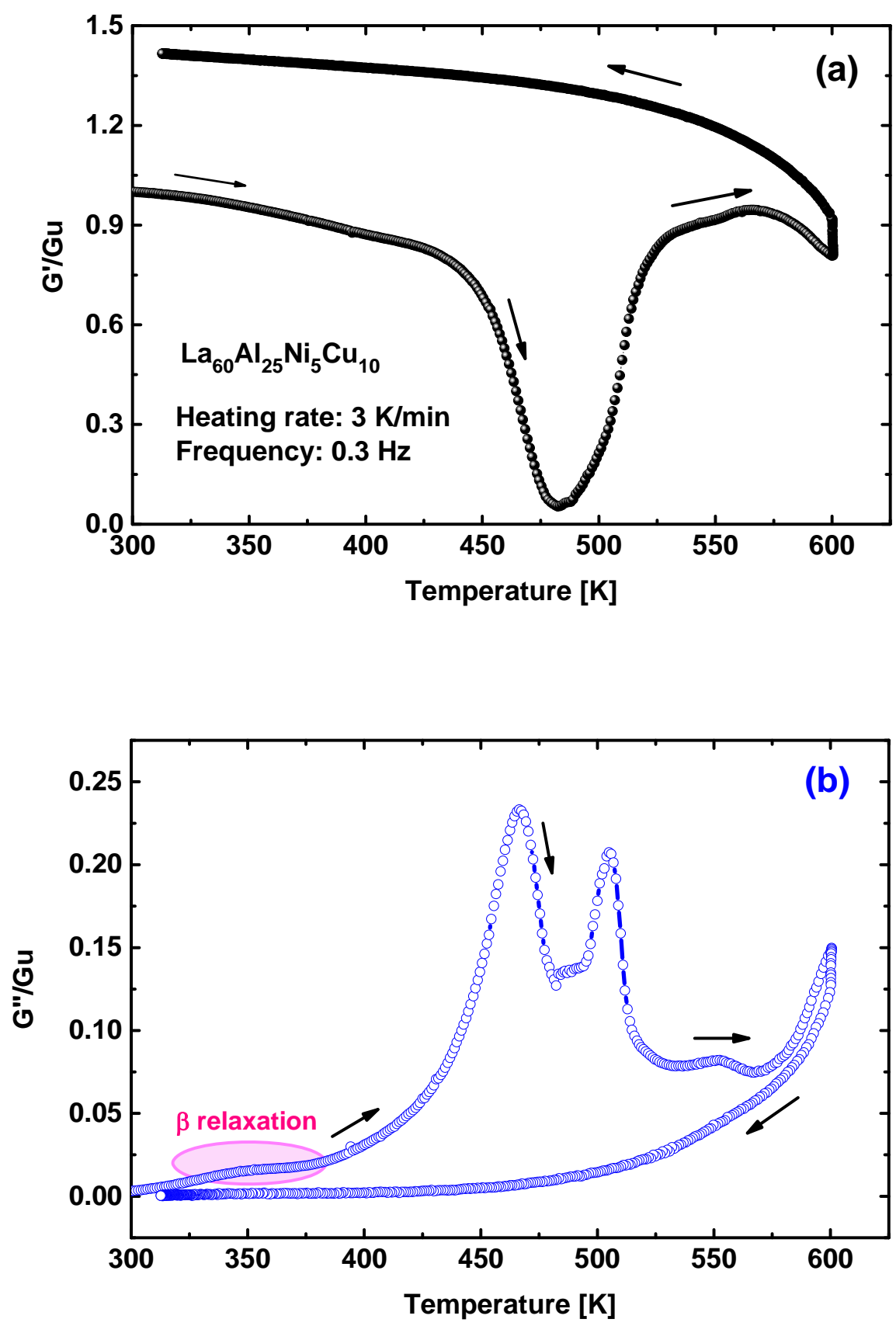
Fig.1 Normalized storage modulus G'/Gu (a) and loss modulus G"/Gu (b) of $\mathrm{La}_{60} \mathrm{Al}_{25} \mathrm{Ni}_{5} \mathrm{Cu}_{10}$ metallic glass as a function of temperature at a fixed frequency (Heating rate: $3 \mathrm{~K} / \mathrm{min}$ ). The arrows indicate the heating and cooling processes during the experiments.

It has been reported that the $\beta$ relaxation is related to the physical and mechanical properties of metallic glasses ${ }^{[9,14]}$. In addition, the $\beta$ relaxation of metallic glasses strongly depends on the chemical composition as well. Fig.2 (a) shows the evolution of the normalized loss modulus of $\mathrm{La}_{60} \mathrm{Ni}_{15} \mathrm{Al}_{25-\mathrm{x}} \mathrm{Cu}_{\mathrm{x}}(\mathrm{x}=0,5,10$ and 15) metallic glasses as a function of temperature. Here, $T_{\alpha}$ is the peak temperature of the $\alpha$ relaxation and $\mathrm{G}^{\prime \prime}{ }_{\max }$ is the value of the loss modulus at $\mathrm{T}_{\alpha}$. It is observed that the intensity of $\beta$ relaxation decreases as $\mathrm{Ni}$ is replaced by $\mathrm{Cu}$. In parallel, Fig.2 (b) shows the comparison of the dynamic mechanical relaxation behavior of $\mathrm{La}_{60} \mathrm{Al}_{25} \mathrm{Ni}_{15}, \mathrm{La}_{55} \mathrm{Al}_{25} \mathrm{Ni}_{15} \mathrm{Cu}_{5}$ and $\mathrm{La}_{60} \mathrm{Al}_{20} \mathrm{Ni}_{15} \mathrm{Cu}_{5}$ metallic glasses. With substitution of $\mathrm{La}$ or $\mathrm{Al}$ by $\mathrm{Cu}$, the $\beta$ relaxation of the La-based metallic glasses is suppressed. The results are in good agreement with the previous investigations[cite Zhu?]. From the mixing enthalpy point of view, the $\beta$ relaxation is connected to the large negative mixing enthalpy of the constitutive atoms in metallic glasses ${ }^{[23]}$. The mixing enthalpies for the La-Ni, La-Al, Al-Ni atomic pairs are $-27,-38$ and $-22 \mathrm{KJ} / \mathrm{mol}$, respectively ${ }^{[24]}$. On the contrary, the mixing enthalpy of $\mathrm{Cu}-\mathrm{Ni}$ and $\mathrm{Cu}-\mathrm{Al}$ are +4 and $-1 \mathrm{KJ} / \mathrm{mol}$, respectively. As suggested by Zhu et al. ${ }^{[12]}$, by introducing $\mathrm{Cu}$ into the LaNiAl metallic glass system, the mixing enthalpy is less negative, which leads to less pronounced $\beta$ relaxation in the metallic glasses. Similar results have been reported in the CuZrAlDy metallic glass system ${ }^{[25]}$. 

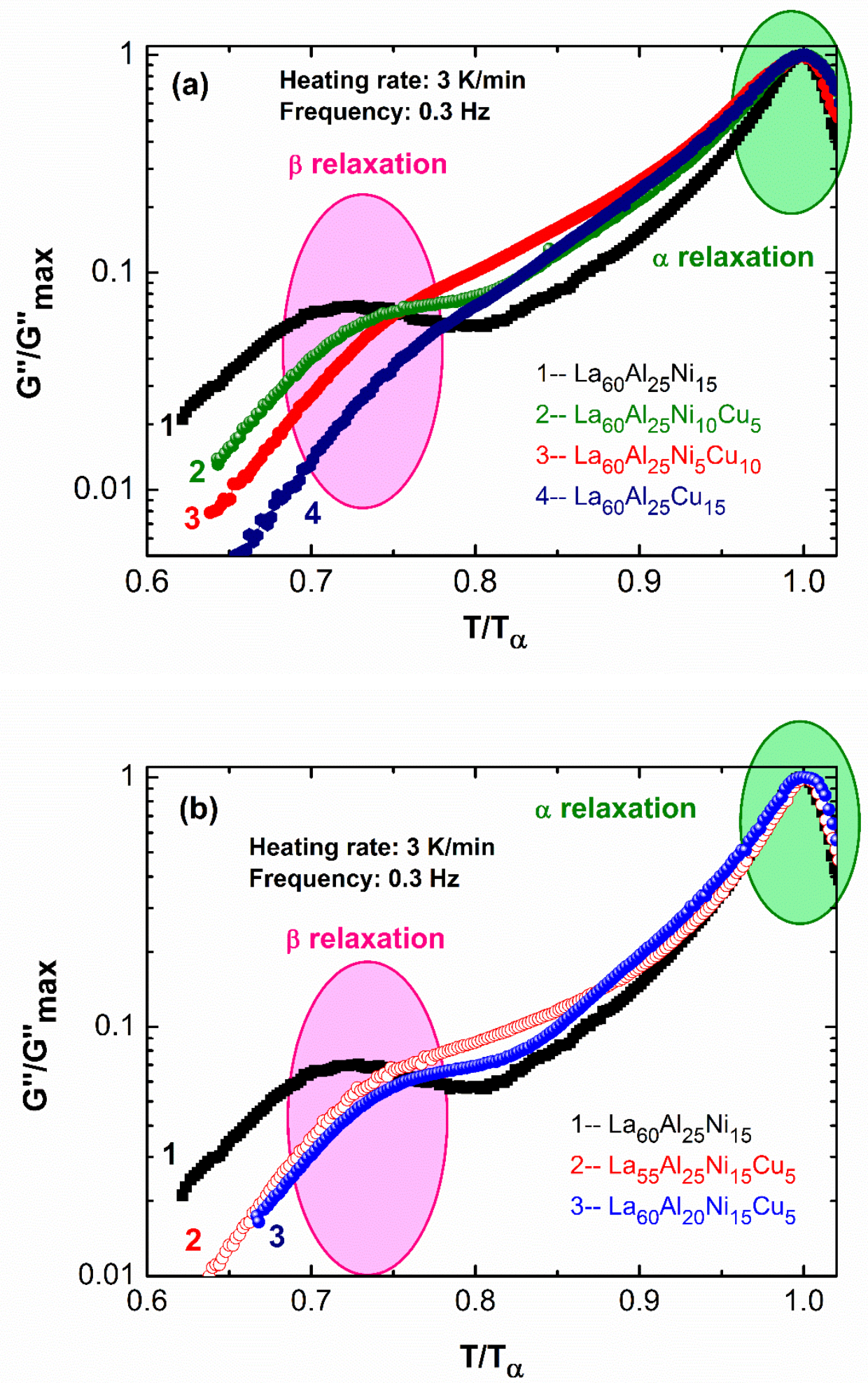

Fig.2 Effect of the chemical composition on the $\beta$ relaxation in La-based metallic glasses. (a) Normalized loss modulus of the $\mathrm{La}_{60} \mathrm{Ni}_{15} \mathrm{Al}_{25-\mathrm{x}} \mathrm{Cu}_{\mathrm{x}}(\mathrm{x}=0,5,10$ and 15) metallic glasses. (b) Normalized loss modulus of $\mathrm{La}_{60} \mathrm{Al}_{25} \mathrm{Ni}_{15}, \mathrm{La}_{55} \mathrm{Al}_{25} \mathrm{Ni}_{15} \mathrm{Cu}_{5}$ and $\mathrm{La}_{60} \mathrm{Al}_{20} \mathrm{Ni}_{15} \mathrm{Cu}_{5}$ metallic glasses. Compared with the $\mathrm{La}_{60} \mathrm{Al}_{25} \mathrm{Al}_{15}, \beta$ relaxation of La55 $\mathrm{Al}_{25} \mathrm{Ni}_{15} \mathrm{Cu}$ bulk metallic glass is suppressed. By decreasing of the $\mathrm{Al}$ content, the $\beta$ relaxation is suppressed as well. 
In order to well reveal the dynamic mechanical relaxation of the La-based metallic glasses, the isothermal experiments have been performed with various stress frequencies at different temperatures. Fig.3 shows the loss modulus $G$ " of the $\mathrm{La}_{60} \mathrm{Al}_{25} \mathrm{Ni}_{5} \mathrm{Cu}_{10}$ metallic glass at different temperatures as a function of frequency (Here only the temperatures below the glass transition temperature $T_{g}$ are shown, mainly focusing on the $\beta$ relaxation). It should be stressed that atomic mobility of metallic glasses strongly depend on the temperature and driving frequency. In general, the loss modulus $\mathrm{G}^{\prime \prime}$ increases by decreasing the frequency at a given temperature. Additionally, the loss modulus G" increases by increasing the temperature at a fixed frequency. Compared to the $\mathrm{La}_{60} \mathrm{Al}_{25} \mathrm{Ni}_{15}$ metallic glass, there is a hump rather than an evident $\beta$ relaxation peak in the loss modulus $G^{\prime \prime}$ spectra of the $\mathrm{La}_{60} \mathrm{Al}_{25} \mathrm{Ni}_{5} \mathrm{Cu}_{10}$ metallic glass.

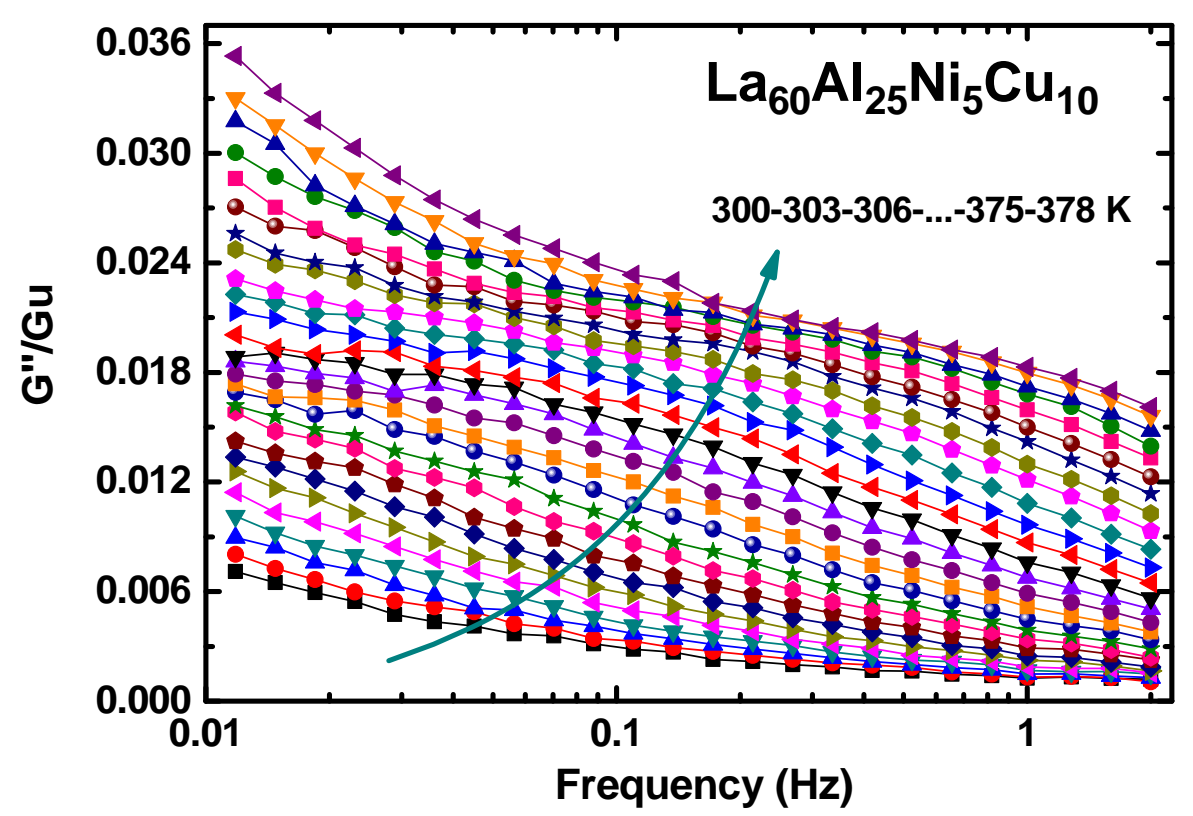

Fig.3. Normalized loss modulus $\mathrm{G}^{\prime \prime} / \mathrm{G}_{u}$ in $\mathrm{La}_{60} \mathrm{Al}_{25} \mathrm{Ni}_{5} \mathrm{Cu}_{10}$ metallic glass as a function of frequency at different temperatures $(330$ to $378 \mathrm{~K}$ by an interval of $3 \mathrm{~K}$ from down to up).

Master curves of glassy materials can be established in the framework of the timetemperature superposition (TTS) principle ${ }^{[6]}$. Fig.4 shows the normalized master curves of the $\mathrm{La}_{60} \mathrm{Ni}_{15} \mathrm{Al}_{25-\mathrm{x}} \mathrm{Cu}_{\mathrm{x}}(\mathrm{x}=0,5,10$ and 15) metallic glasses. The validity of the TTS in the studied La-based metallic glasses is verified. Based on the master curves of 
the metallic glasses, the same tendency of $\beta$ relaxation is observed as isochronal condition. That means the $\beta$ relaxation is suppressed by increasing the content of $\mathrm{Cu}$.

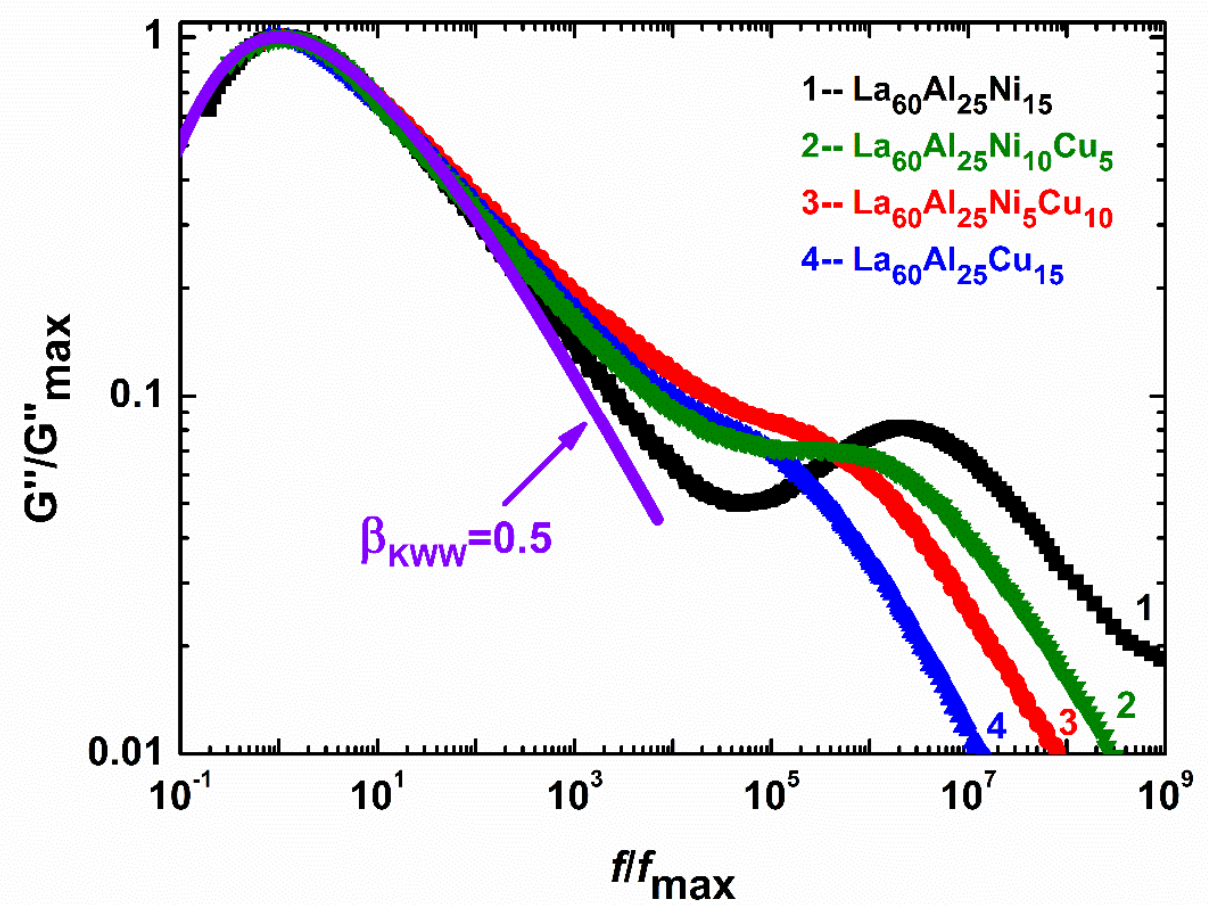

Fig.4 Master curves of the $\mathrm{La}_{60} \mathrm{Ni}_{15} \mathrm{Al}_{25-\mathrm{x}} \mathrm{Cu}_{\mathrm{x}}\left(\mathrm{x}=0,5,10\right.$ and 15) metallic glasses. G" ${ }_{\max }$ is the peak of $\alpha$ relaxation, located at $f_{\max }$. The solid line is the KWW function with the parameter $\beta_{\mathrm{Kww}}=0.5$.

It has been reported that the $\alpha$ relaxation of the amorphous materials can be well described by a Kohlrausch-Williams-Watts (KWW) relaxation equation [26]:

$$
\begin{aligned}
& G^{\prime \prime}(\omega)=\Delta G_{\alpha} L_{i \omega}\left[-\frac{d \varphi_{\alpha}\left(t, \tau_{\alpha}\right)}{d t}\right] \\
& \text { with } \varphi_{\alpha}\left(t, \tau_{\alpha}\right)=\exp \left[-\left(t / \tau_{\alpha}\right)^{\beta_{K W W}}\right]
\end{aligned}
$$

where $L_{\mathrm{i} \omega}$ is the Laplace transform, the Kohlrausch exponent $\beta_{\mathrm{KWw}}$ ranges from 0 to 1. The relaxation strength $\Delta G=G_{\mathrm{u}}-G_{\mathrm{r}}\left(G_{\mathrm{u}}\right.$ is the unrelaxed modulus, $G_{r}$ is the relaxed modulus)

It is worth noting that for all the La-based metallic glasses, the relaxation function of the $\alpha$ relaxation process is associated with the Kohlrausch exponent $\beta \mathrm{Kww} \sim 0.5$. The current results are in good agreement with the previous investigations on other metallic glasses and glassy materials ${ }^{[12,25,27-30]}$. It is confirmed that $\beta_{\mathrm{KwW}}=0.5$ can be adopted to describe the $\alpha$ relaxation of the metallic glasses independently of the chemical composition. 


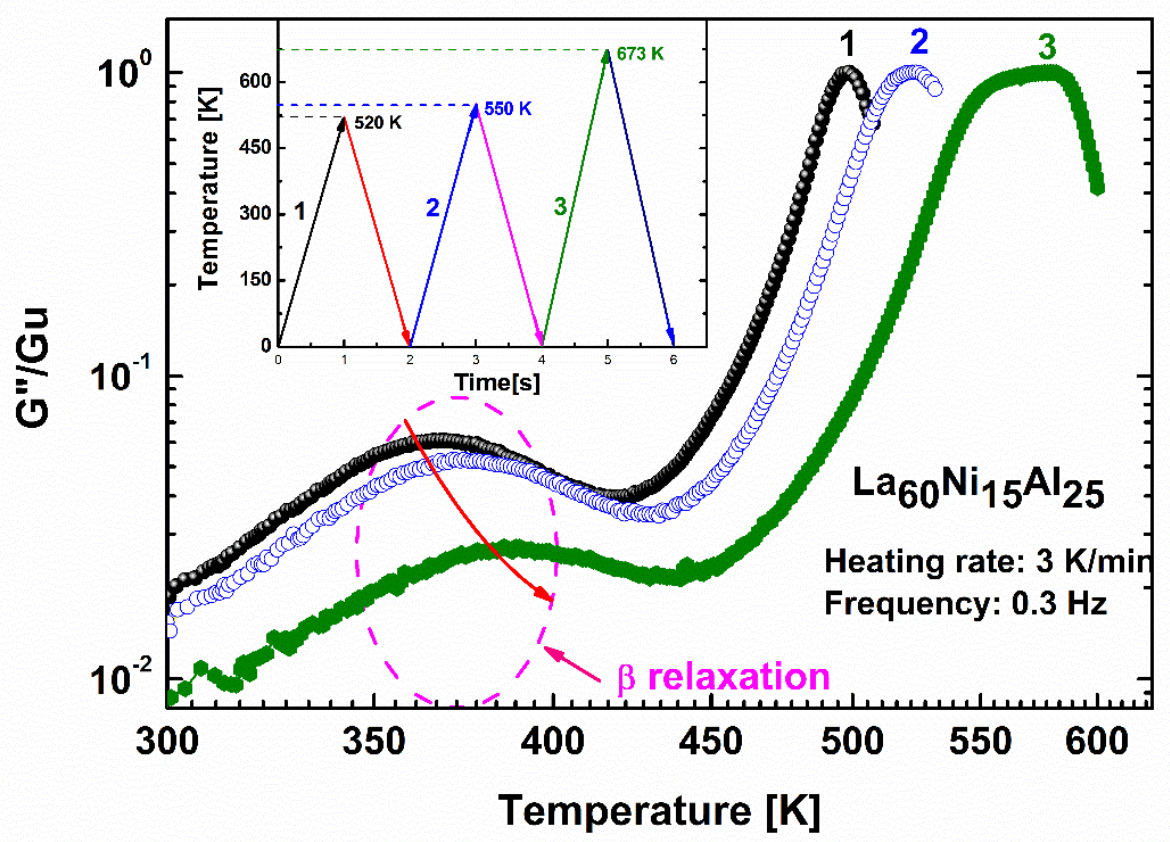

Fig.5 Temperature dependence of the normalized loss modulus in $\mathrm{La}_{60} \mathrm{Ni}_{15} \mathrm{Al}_{25}$ bulk metallic glass (heating rate: $3 \mathrm{~K} / \mathrm{min}$ and driving frequency: $3 \mathrm{~Hz}$ ): (1) As-cast, (2) After thermal treatment at $520 \mathrm{~K}$ and (3) After thermal treatment at $550 \mathrm{~K}$.

Fig. 5 shows the physical aging on the $\alpha$ and $\beta$ relaxations in $\mathrm{La}_{60} \mathrm{Ni}_{15} \mathrm{Al}_{25}$ bulk metallic glass. It should be noted that the intensity of the $\beta$ relaxation was reduced by introduction of the partial crystallization during thermal treatment. Physically, the $\beta$ relaxation of glass system is mainly connected to the local and non-cooperative movements of atoms. In the framework of the "flow units" theory, it is well established that the $\beta$ relaxation of metallic glasses is associated with the flow units. The concentration of the flow units decreases by physical aging below the glass transition temperature or induction of nano-crystallization. In parallel, it is evident that the peak of the $\beta$ relaxation shifts to higher temperature compared with as-cast one. The result is in good accordance with our previous research ${ }^{[31]}$. Recently, Wang et al. reported that the activation energy of the $\beta$ relaxation increases by physical aging below the glass transition temperature $T_{g}{ }^{[32]}$. Accordingly, the $\beta$ relaxation of the La-based metallic glass shifts to low frequency domain by aging below glass transition temperature $T_{g}{ }^{[33]}$.

\section{Conclusion}

In summary, the $\beta$ relaxation of La-based metallic glasses has been studied by mechanical spectroscopy. The current research reveals that $\beta$ relaxation of the metallic 
glasses strongly depends on the chemical composition. The results support that the intensity of $\beta$ relaxation decreases by the addition of $\mathrm{Cu}$ to replace $\mathrm{Ni}$ for the $\mathrm{LaCuNiAl}$ glass. Partial substitution of $\mathrm{La}$ by $\mathrm{Cu}$ into the LaNiAl metallic glass system has a similar effect. In the current work, the $\alpha$ relaxation of the La-based metallic glasses can be described by the KWW equation with a $\beta_{\mathrm{KWw}} \sim 0.5$. It is also found that the intensity of the $\beta$ relaxation decreases by the onset of nano-crystallization in the La-based metallic glass.

\section{Acknowledgements}

This work is supported by Natural Science Foundation of China (Grant Nos. 51401192, 51611130120 and 11572249), the Natural Science Foundation of Shaanxi Province (No. 2016JM5009), the Aeronautical Science Foundation of China (2015ZF53072). The Project was supported by State Key Laboratory of Materials Processing and Die \& Mould Technology, Huazhong University of Science and Technology (P2016-12). DC acknowledges the support from MINECO (FIS201454734-P), and Generalitat de Catalunya (2014SGR00581).

\section{References}

[1] M.W. Chen, Annu. Rev. Mater. Res. 38 (2008) 445-469.

[2] W.H. Wang, Prog. Mater. Sci. 57 (2012) 487-656.

[3] A. Inoue, Acta Mater. 48 (2000) 279-306.

[4] P.G. Debenedetti, F.H. Stillinger, Nature 410 (2001) 259-267.

[5] G. P. Johari, M.Goldstein, J. Chem. Phys. 53 (1970) 2372-2388.

[6] K.L. Ngai, Relaxation and Diffusion in Complex Systems (Springer,2011)

[7] J.C. Qiao, J.M. Pelletier, N. Li, Y. Yao, J. Iron Steel Res. Int. 23 (2016) 19-23.

[8] J. Kong, Z.T. Ye, W. Chen, X.L. Shao, K.H. Wang, Q. Zhou, Mater. Des. 88 (2015) 69-74.

[9] C.R. Liu, E. Pineda, D. Crespo, Metals 5 (2015) 1073-1111.

[10] W.H. Wang, P. Wen, X.F. Liu, J. Non-Cryst. Solids 352 (2006) 5103-5109.

[11] J.C. Qiao, J.M. Pelletier, J. Mater. Sci. Technol. 30 (2014) 523-545.

[12] Z. G. Zhu, Y. Z. Li, Z. Wang, X. Q. Gao, P. Wen, H. Y. Bai, K. L. Ngai, W. H. Wang, J. Chem. Phys. 141 (2014) 084506.

[13] J.C. Qiao, J.M. Pelletier, J. Appl. Phys. 112 (2012) 083528.

[14] H.B. Yu, W.H. Wang, K. Samwer, Mater. Today 16 (2013) 183-191.

[15] Z. Wang, H. B. Yu, P. Wen, H. Y. Bai, W. H. Wang, J. Phys.: Condens.

Matter 23 (2011) 142202.

[16] H. Okumura, A. Inoue, T. Masumoto, Mater. Trans. JIM 32 (1991) 593-598.

[17] D. Nguyen, Z. G. Zhu, B. Pringle, J. Lyding, W. H. Wang, M. Gruebele, Phys. Chem. Chem. Phys. 18 (2016) 16856-16861.

[18] J.C. Qiao, Q. Wang, D. Crespo, Y. Yang, J.M. Pelletier, Chin. Phys. B 26 (2017) 016402. 
[19] Q. Wang, S.T. Zhang, Y. Yang, Y.D. Dong, C.T. Liu, J. Lu, Nat. Commun. 6 (2015) 7876.

[20]S.Etienne, J.Y. Cavaillé, J.Perez, R.Point, M.Salvia, Rev. Sci. Inst. 53 (1982) 12611266.

[21] J.M. Pelletier, D.V. Louzguine-Luzgin, S, Li, A, Inoue, Acta Mater. 59 (2011) 2797-2806.

[22] J.M. Pelletier, J. Non-Cryst. Solids 354 (2008) 3666-3670.

[23] H.B. Yu, K. Samwer, W.H. Wang, H.Y. Bai, Nat. Commun. 4 (2013) 2204.

[24] A. Takeuchi, A. Inoue, Mater. Trans. 46 (2005) 2817-2829.

[25] J.C. Qiao, Y. Yao, J.M. Pelletier, L.M. Keer, Inter. J. Plast. 82 (2016) 62-75.

[26] G. Williams, D.C. Watts, Trans. Faraday Soc. 66 (1970) 80-85.

[27] J.C. Qiao, R. Casalini, J.M. Pelletier, Y. Yao, J. Non-Cryst. Solids 447 (2016) 8590.

[28] J.C. Qiao, R. Casalini, J.M. Pelletier, J.Non-Cryst. Solids 407 (2015) 106-109.

[29] L.M. Wang, R.P. Liu, W.H. Wang, J. Chem. Phys. 128 (2008) 164503.

[30] P.F. Li, Y.Q. Zhang, Z.M. Chen, P. Gao, T. Wu, L.M. Wang, Sci. Rep. 7 (2017) 40547.

[31] J.C. Qiao, Y.J. Wang, J.M. Pelletier, L.M. Keer, M.E. Fine, Acta Mater. 98 (2015) 43-50.

[32] Z. Wang, K.L. Ngai, W.H. Wang, J. Appl. Phys. 118 (2015) 034901.

[33] J.C. Qiao, R.Casalini, J.M. Pelletier, J. Chem. Phys. 141 (2014) 104510. 